\title{
STUDY OF THE PERFORMANCE OF AN INCLINED ANNULAR CRANK TWO-PHASE THERMOSYPHON
}

\author{
Mostafa A. Abd El-Baky \\ Mechanical Power Engineering Department, \\ Faculty of Engineering, Menoufia University, \\ Shebin El-Kom, Egypt.
}

\begin{abstract}
An experimental study is conducted on the internal cooling-heating crank thermosyphon oriented with respect to horizontal. Bent geometry of the thermosyphon is sometimes needed to use because of the limited space for the straight thermosyphon to be installed. Therefore, in the present study, the crank-shape thermosyphon is investigated on the heat transfer coefficients and the critical heat fluxes. Experiments on water filled tubes are conducted to investigate the internal cooling heating offset thermosyphon. Heat transfer in tilted annular two phase closed thermosyphon has been studied experimentally. The effect of heat flux, inclination angle and the evaporator to condenser length ratio on the heat transfer coefficient has been investigated in details. The evaporator to condenser ratio was varied from 0.25 to 1.6 . The inclination angle was changed to be $15^{\circ}, 30^{\circ}, 45^{\circ}, 60^{\circ}$ and $90^{\circ}$. The heat flux was taken as: $1.33,2.66,3.99,5.32$ and $6.65 \mathrm{~kW} / \mathrm{m}^{2}$. The results indicated that, the maximum overall heat transfer coefficient occurs at evaporator length to condenser length ratio 0.5 with an inclination angle of $60^{\circ}$. At evaporator to condenser length ratio of unity, the maximum overall heat transfer coefficient occurs at $\mathrm{L}_{\mathrm{e}}=\mathrm{L}_{\mathrm{c}}=20 \mathrm{~cm}$. The thermal performance increases when the heat transfer rate was increased.
\end{abstract}

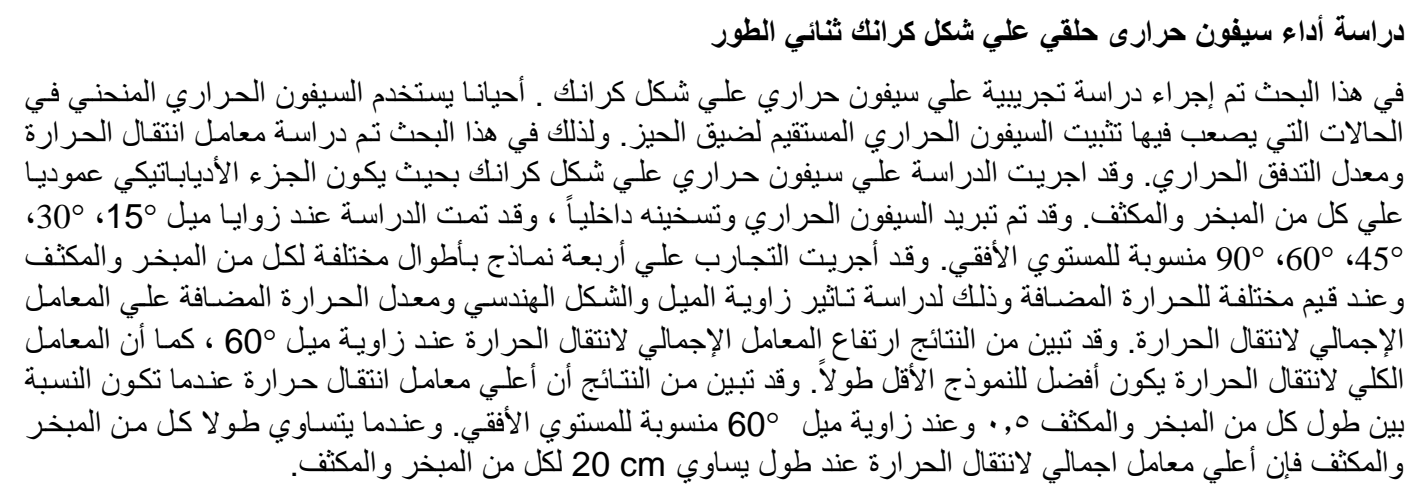

Keywords: Internal cooling-heating offset thermosyphon, flooding phenomena

\section{1- INTRODUCTION}

A closed two phase thermosyphon is known as wickless heat pipe with condenser at high level compared to the evaporator. In constructing the device, a small amount of liquid is filled into a closed tube occupying a fraction of the tube volume. Heat is added through the evaporator section which maintained at a lower position. Evaporation of the filled liquid takes place and the generated vapor moves upward to the condenser section. In the condenser, heat is removed and the vapor condenses.
The condensate falls down to the evaporator section along the pipe wall.

Heat transfer in the thermosyphon is considered to be affected by many factors. These factors includes: type of the working medium and its quantity, tube geometry, ratio of the evaporator length to condenser length, heat flux and operating pressure. In view of the complicated hydrodynamic and thermal processes, the heat transfer performance of a twophase closed thermosyphon is 
mainly explored by experimental measurement. Lee and Mital [1] investigated experimentally the heat transfer performance of two phase closed thermosyphon. They noted that, heat transfer coefficient is very sensitive to the operating pressure and in fact rapidly increases with the increase of pressure. Bezrondny and Elekseyenko [2] carried out experiments to check the effect of fill quantity on the heat transfer. They found that, optimal heat transfer performance can be obtained when fill quantity is over $50 \%$ of the evaporator volume. Undeveloped boiling occurs in the heat supply zone at low heat load while at high heat load developed boiling prevails [3].

By using an annular thermosyphon with a glass outer cylinder, Andros and Florschuetz [4] visualized the flow patterns in the device. For small and intermediate fills, four basic flow regimes were observed in the evaporator section for increasing heat load: a small continuous film with surface evaporator, breakdown of the smooth continuous film into a series of stable rivulets, a wavy film with unstable rivulets, and a wavy film with bubble nucleation occurring in the unstable rivulets. Obviously, at a very high heat input, complete dry out in the evaporator results. Similar flow visualization was conducted by Rosler et al [5]. The heat transfer coefficient in the condenser is normally derived from the Nusselt solution for film wise condensation [6]. Based on 2529 data points Grob [7] classified the heat transfer processes in the evaporator into a two-phase natural convection regime and a nucleate boiling regime.

Effects of the heat pipe inclination on the heat transfer performance were examined by Semena and Kiseelev [3], Feldman and Srinivassan [8], Nigishi and Sawada [9] and Groll and Spendel [10]. Maximum heat transfer occurs when the inclination angle is between $20^{\circ}$ and $40^{\circ}$ for water and more than $5^{\circ}$ for ethanol. Also, Groll and Spendel noted that, maximum heat flux results at an inclination of around $40^{\circ}$.

Heat transfer performance of the device at high pressure and near critical state was studied by Gross and Hahne [11 and 12]. Their results indicated that, combined heat transfer in the heating and cooling zones renders an overall performance with optimal conditions at an inclination angle of about $\varphi=40^{\circ}$, a small heat flow rate and pressures $0.9<p / p c<1.0$ as long as no film boiling occurs. Heat transport characteristics of a cryogenic two-phase nitrogen thermosyphon were studied experimentally by Nakano et al [13] to investigated the transfer rate over a wide dynamic range from near the triple point to the critical point. It was found that the maximum heat transfer rate is governed by the interaction between the vapor flow and the returning liquid film flow along the wall in the evaporator section, even near the critical point.

The heat transfer in a vertical annular two phase closed thermosyphon has been studied experimentally with distilled water as a working fluid by Abd El-Aziz [14]. The effect of heat flux, liquid fill charge and evaporator to condenser length ratio on the overall heat transfer coefficient was investigated. The results indicated that, the maximum overall heat transfer coefficient occurred at an evaporator to condenser length ratio ranged between 0.33 to 1.0 and the liquid fill charge was $16 \%$ which based on the total thermosyphon volume. A correlation between the above three parameters was suggested to calculate the overall heat transfer coefficient.

Imura et al [15] studied experimentally the heat transfer characteristics in a two-phase vertical crankshape closed thermosyphon with horizontal adiabatic section. Performance of a two phase closed thermosyphon was experimentally investigated by Kannan and Natarajan [16]. The experiments were carried out for different filling ratios of 30 to $90 \%$ with input heat transfer rates of 0 to $1000 \mathrm{~W}$ and for various working fluids such as distilled water, ethanol, methanol and acetone. Investigations were focused to find the influence of the filling ratio, maximum heat transport capability for various working fluids in a vertical two phase closed thermosyphon. The maximum heat transport capability was found to be high for water compared to other fluids such as ethanol, methanol and acetone, at the operating temperatures higher than $40^{\circ} \mathrm{C}$.

In the last few years ago, situations appeared in which the size, shapes and locations of the source and sink demanded the use of nonlinear loops. Thus, the urgent need for additional configurations for these uncommon and new applications has rapidly increased. In this concern, Lock and Ladoon $[17,18]$ studied the influence of the tilt angle on natural convection in water filled right angled elbow thermosyphon for Rayleight number less than $10^{7}$. The obtained data indicated the existence of fully mixed and impeded regions of flow. Here, the designer is restricted to simple common circumstances in which the stationary heat source lies immediately adjacent and largely beneath the heat sink. The cranked or offset tubular thermosyphon is one example of a variety of different configurations of highly promising flexibility for various applications. In such a configuration the cranked thermosyphon consists of two parallel sections. One is heated and the other is cooled and the two is 
separated by an adiabatic section. Shung et al [19] studied the effect of cooling water temperatures, fluid fill ratio and evaporator type on the heat transfer of a loop thermosyphon. They found that, the wick structure can enhance the heat transfer effects directly.

Very little information is available on the cranked or offset thermosyphon. The most interesting studies are those done by Lock et al [20 - 22]. They studied the effect of tilt angle, Rayligh number and flow regimes on natural convection in a cranked water filled single-phase thermosyphon. In their research, the heated-cooled length ratio was kept constant $\left(\mathrm{L}_{\mathrm{e}} / \mathrm{L}_{\mathrm{c}}=\right.$ $1)$, and the flow regime describing the thermal behavior was based on studies given in [23, 24].

From the available literature review, the parameters suggested to have some effects on the performance of the two phase closed thermosyphon still need more investigations in order to satisfy a quite acceptable agreement of the results. Therefore, the main objective of this work is to obtain experimental information on the interactive influences of the geometric effects, in the form of cooled heated length ratio on the heat transfer of an offset annular tilted two phase closed thermosyphon.

\section{2- EXPERIMENTAL WORK:}

\section{2-1 Test Rig:}

The schematic diagram of the experimental test rig and test section is shown in Fig. 1. The thermosyphon is made of a smooth copper tube of inside diameter $26.3 \mathrm{~mm}$ and $1 \mathrm{~mm}$ wall thickness and variable total length. Two types of the thermosyphon were used. With respect of the first type, the length of the evaporator equal to the length of the condenser. Four models were used with evaporator and condenser lengths equal to 20,40, 60 and $80 \mathrm{~cm}$. With respect of the second type, the length of the condenser is constant and equal to 20 $\mathrm{cm}$, but the evaporator length is changed to be 20,40 , 60 and $80 \mathrm{~cm}$. The outside tube diameter, for the all types of the thermosyphon, is constant. The length of adiabatic section for all modules is constant at $8 \mathrm{~cm}$. A copper tube of $10.2 \mathrm{~mm}$ inner diameter and 1.2 $\mathrm{mm}$ wall thickness is installed inside condenser tube for cooling purposes. Cooling water was flowing through the inner tube. It enters from the bottom section. A constant head tank is located above the head of the thermosyphon tube and connected to the cooling section through a rubber tube. The make up water provides the constant head tank by a float valve to ensure that the flow of water is nearly steady. The flow rate of cooling water is controlled with the aid of a valve and a Rota meter.
The heating of the evaporator was provided directly by a constant and uniformly heat flux being created by $500 \mathrm{~W}$ Nickel-Chrome resistive heater. Chromic electrically resistant wire taped inside small ceramic shields and put inside the inner tube of the evaporator. A $50 \mathrm{~mm}$ thickness of glass wool thermal insulation was fixed around the thermosyphon to ensure minimum heat loss to-or gained from - the surrounding.

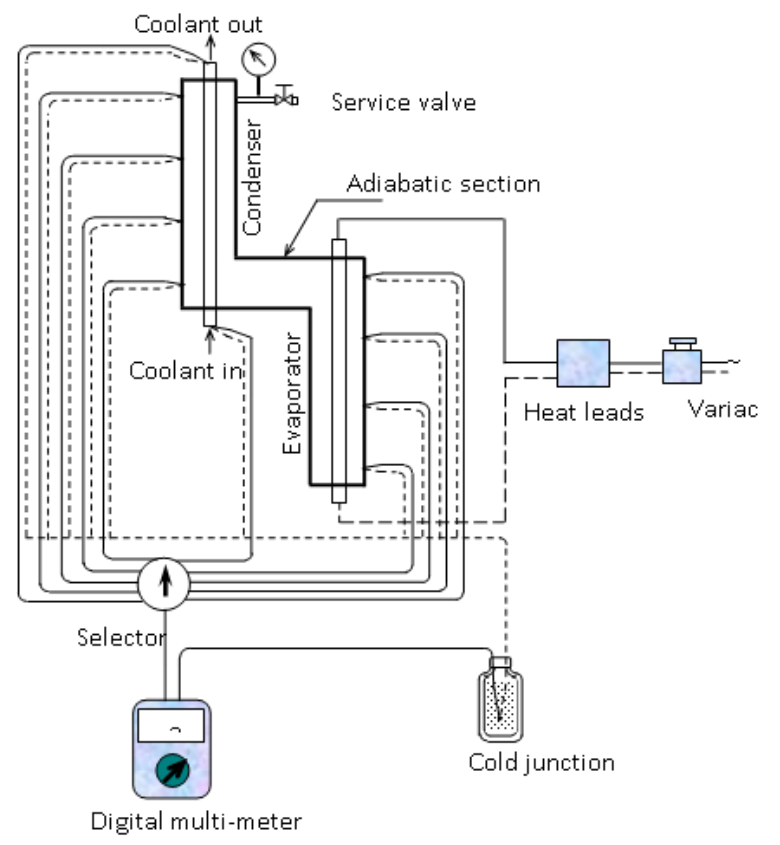

Fig. (1) Experimental apparatus

\section{2-2 Measurements}

No attempt was made to measure the heat removed by the cooling water because, under steady condition it is equal to the net heat supplied in the heated section. The later was calculated by subtracting the heat leakage from the gross supply rate. The electrical power was measured in the usual way with the aid of a Wattmeter with an accuracy of $1 \%$. The heat leakage was determined from a calibration test under taken before perform the experiments. This test consisted of plotting the power supplied against the difference in temperature between the tube wall and the room air when tube was covered with thermal insulation.

Typically, the leakage was about $4 \%$ of the gross supply rate. Wall temperature gradient was measured with the aid of Chromel-Alumel thermocouples 
located at an equal interval of $5 \mathrm{~cm}$ along the evaporator, adiabatic and condenser wall lengths. Wall measuring thermocouples junctions were laid in two axial opposite grooves, and were covered by high thermal resistive copper powdered epoxy mixture. All thermocouples were specially prepared and calibrated. The signals from the thermocouples were channeled through a selecting switch and read on a digital multi-meter with an accuracy of $0.1{ }^{\circ} \mathrm{C}$. The cooling water mass flow rate was measured in the usual way with a variable area Rota meter with an accuracy of $2 \%$. Inclinations were measured with a simple protractor and a level.

\section{2-3 Test Procedure}

Before beginning of the test program, the apparatus is first cleaned and charged. The cleaning is attained to the tube surfaces with benzene followed by alcohol then distilled water, which is chosen as a working medium. Assembly of the apparatus with different lengths of the evaporator and condenser for two types of the thermosyphon, the internal pressure inside the thermosyphon tube was lowered until the vacuum pump was shut off. The apparatus was allowed to set for several hours in order to detect any leakage. A quantity of distilled water was measured and charged. The charged amount of distilled water was measured to be equal $40 \%$ of the evaporator volume. The apparatus was perfectly sealed to protect any leakage. The main test procedure proceeded as follows: having chosen the selected configuration and the evaporator length. The apparatus was filled with an adequate amount of the working fluid.

The cooling water was allowed to flow and the power of the heater tap was set at a convenient value. The system was allowed to be stabilized for a period of about two hours, during which necessary adjustment in the input power and the cooling water flow rate took place in order to achieve approximately steady state condition. The readings gross power and the mass flow rate of the cooling water were also simultaneously recorded. Having determined the net power supply and the average wall temperature of each of the evaporator and the condenser, the heat flux density "q" based in the evaporator surface area was then evaluated to determine the overall heat transfer coefficient by the following equation introduced by Chi [25];

$\mathrm{U}=\frac{q}{T_{e, m}-T_{c, m}}=\frac{1}{\frac{1}{h_{e}}+\frac{1}{h_{c}}}$

$\mathrm{h}_{\mathrm{e}}=\frac{q}{T_{e, m}-T_{a, m}}$
$\mathrm{h}_{\mathrm{c}}=\frac{q}{T_{a, m}-T_{c, m}}$

where: $T_{e, m}$ and $T_{c, m}$ are the mean temperature of evaporator and condenser respectively.

$\mathrm{T}_{\mathrm{a}, \mathrm{m}}$ is the mean temperature of the adiabatic section.

$h_{e}$ and $h_{c}$ are the convective heat transfer coefficient for the evaporator and condenser respectively.

The procedure was then repeated following an increase in the power supplied. The complete procedure was followed for another modified condition. The modification included the change in tilt angle and another thermosyphon tube.

\section{3- RESULTS AND DISCUSSION:}

The performance of thermosyphon is affected by many factors such as the amount of heat input, fluid charge and inclination angle with respect to horizontal with condenser higher than the evaporator. When heat is supplied to the evaporator section, the liquid starts to boil on the wall. The vapor flows upwards to the condenser section where it condenses on the inner wall of the tube. Counter currents to this up streaming vapor, the condensate flows down the walls into the liquid in the lower part of the tube. Thus, in such a device two processes take place, namely, evaporation in the evaporator section as well as condensation in the condenser. Both processes greatly govern the performance of two phase closed thermosyphon.

\section{3-1 Wall Temperature Distribution Along the Thermosyphon:}

The wall temperature distribution was measured along the thermosyphon length and plotted in Fig. (2), for $\mathrm{L}_{\mathrm{e}}=\mathrm{L}_{\mathrm{c}}=0.2 \mathrm{~m}$ and at an inclination angle $\theta=$ $60^{\circ}$. The heat flux is changed to be $1.33,2.66,3.49$, 5.32 and $6.65 \mathrm{~kW} / \mathrm{m}^{2}$. The figure shows that, the local wall temperature increases slightly at the free end of the evaporator and then decreases gradually in the direction of adiabatic section. This is because condensation of vapor may cause a liquid puddle at the evaporator.

At the condenser section, the temperature decreases to the free end of the condenser. It referred to the movement upward of the vapor phase as a result of its low density, the presence of vapor in the free end of condenser leads to change of thermal resistance at all stations of the condenser section. This difference in thermal resistance tends to be small increase in the temperature at the free end of condenser. Also, the 
local temperature increases with the increase of the heat transfer rate for all positions. An increase of heat flux results in a rise of vapor superheat near the wall and consequently to greater number of active nucleation sites. Evaporation into the rising bubbles produces additional heat sinks in the liquid, especially in the upper parts of the heating zone where vapor accumulates.

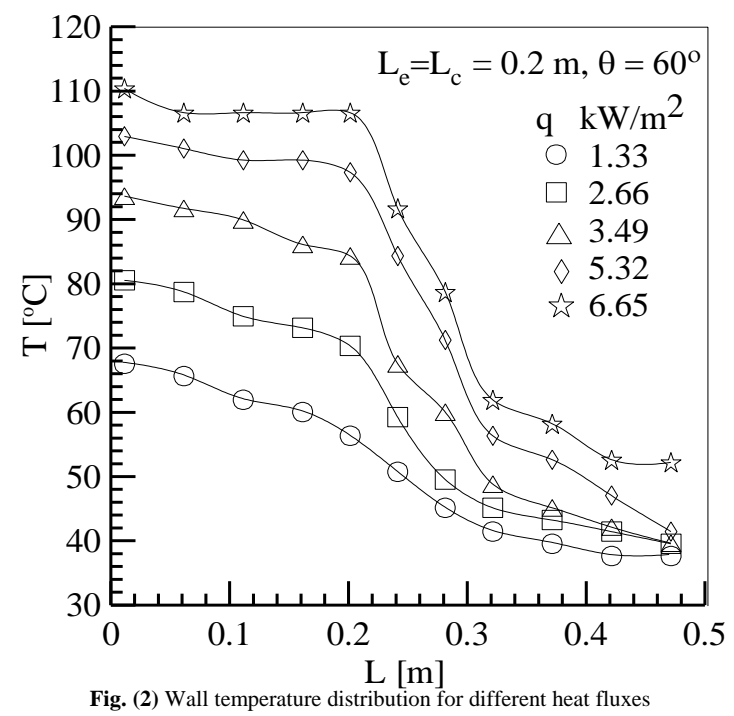

Figure (3) shows the temperature distribution along the thermosyphon for $\mathrm{L}_{\mathrm{e}}=\mathrm{L}_{\mathrm{c}}=0.2 \mathrm{~m}$. The heat transfer rate was $\mathrm{q}=2.66 \mathrm{~kW} / \mathrm{m}^{2}$. The inclination angle $\theta$ is changed to be $15^{\circ}, 30^{\circ}, 45^{\circ}, 60$ and $90^{\circ}$. It is indicated from the figure that, the local temperature along the evaporator section increases with the increase of tilt angle from $15^{\circ}$ to $60^{\circ}$. However, for tilt angle greater than $60^{\circ}$, the values of temperature then decrease. On the other hand, in the condenser section, the local temperature distribution is nearly constant at different tilt angles. The temperature distribution decreases with increasing the tilt angle. This is because the temperature distribution on the container wall, boiling bubbles departed from the bottom corner which played the role of a cavity, it expands rapidly to the full inner diameter of the annular hole and rises up the whole tube. The bubbles are transformed into a film of liquid as it rises along the whole tube wall. The film brakes there and is transformed into many liquid drops. When the thermosyphon was inclined, a large amount of liquid was dashed against the upper of the whole tube.

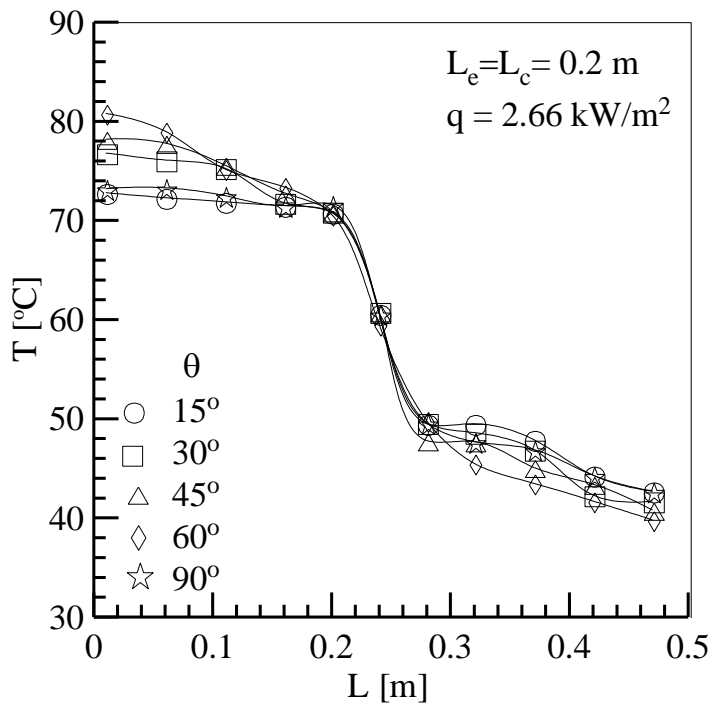

Fig. (3) Wall temperature distribution for different orientations

At an inclination angle of $60^{\circ}$ the dashing tip of the liquid movement reaches the end of the condenser. It is considered that, the heat transfer mechanism in the condenser consisted of the condensation of vapor and forced convection by the dashing liquid. In addition, the fresh condensed surface is exposed to the vapor after the surface has been cleared by the passage of the dashing liquid. Consequently, the heat transfer performance is improved there. The temperature difference between evaporator and condenser has the lowest value in this situation. When the inclination angle was $15^{\circ}$, the liquid movement lessened and the heat transfer rate decreased. 'Thus, at small inclination angle, the dashing motion of the liquid reached to the end of the condenser. Consequently, the heat transfer rate decreases gradually.

In order to clarify the effect of geometry on the wall temperature distribution, the experimental data were plotted in Figs. $(4,5)$ at fixed heat flux $(\mathrm{q}=2.66$ $\left.\mathrm{kW} / \mathrm{m}^{2}\right)$, constant tilt angle $\left(\theta=60^{\circ}\right)$ and different lengths of the evaporator and condenser. It is clear that, from Fig. (4) at $\mathrm{L}_{\mathrm{e}} / \mathrm{L}_{\mathrm{c}}=$ constant $=1.0$ and different lengths of both, the values of wall temperature are high at small length of both the evaporator and condenser and decreasing by increasing the lengths of both evaporator and condenser. 


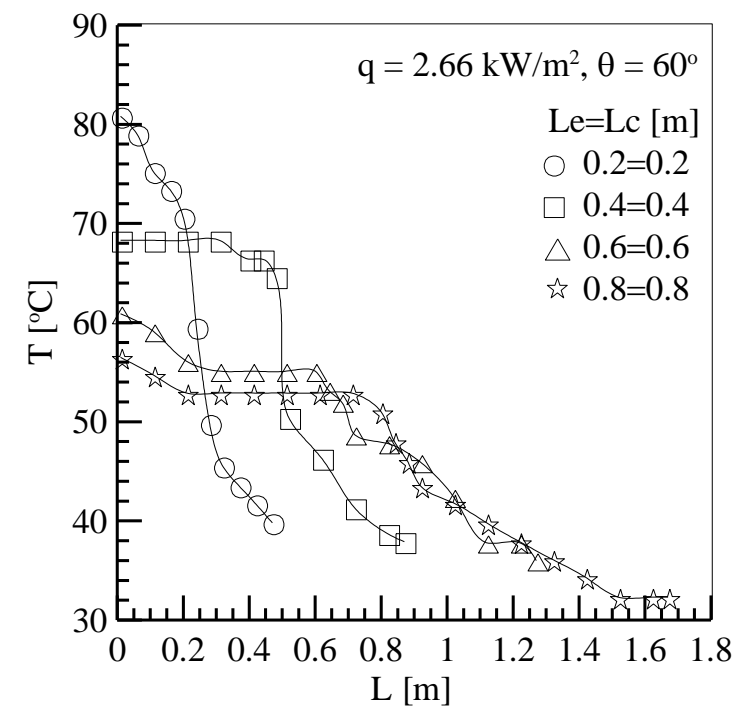

Fig. (4) Wall temperature distribution at different evaporator and condenser lengths

Also, it is noticed from Fig. (5) that, at different values of evaporator length to condenser length ratio of $\left(\mathrm{L}_{\mathrm{e}} / \mathrm{L}_{\mathrm{c}}=0.25,0.5,0.75\right.$ and 1.0$)$ and at constant of both heat flux and tilt angle, the value of wall temperature reaches a peak value at $\mathrm{L}_{\mathrm{e}} / \mathrm{L}_{\mathrm{c}}=0.5$ and is small at both of $\mathrm{L}_{\mathrm{e}} / \mathrm{L}_{\mathrm{c}}=0.25,0.75$ and 1.0. This can be attributed to the intensified boiling process at small evaporator areas. This is because, at a fixed fill charge ratio and long evaporator length and small condenser length, the saturated boiling occupies the long length of the evaporator section resulting in a high vapor fraction. In such case, the convective heat transfer coefficient inside the tube becomes so poor that the electrically provided heat leads.

At the same time, due to the increased concentration of vapor in the upper condenser section, as well as, the relatively greater saturation, the poor condenser performance in such condition leads to break down of the local fluid flow to the evaporator section which in turn suffers from dryness. At the evaporator section, generated bubbles coalesce before they are able to separate from the boiling sites and they form a vapor film between the wall and the liquid. Thus, transition from nucleate to film boiling is attained. This results in a degradation of the convective boiling heat transfer coefficient. This explains the conjunction of poor performance of both condenser and evaporator with low values of wall temperature at higher values of the evaporator to condenser length ratios and the opposite is true.

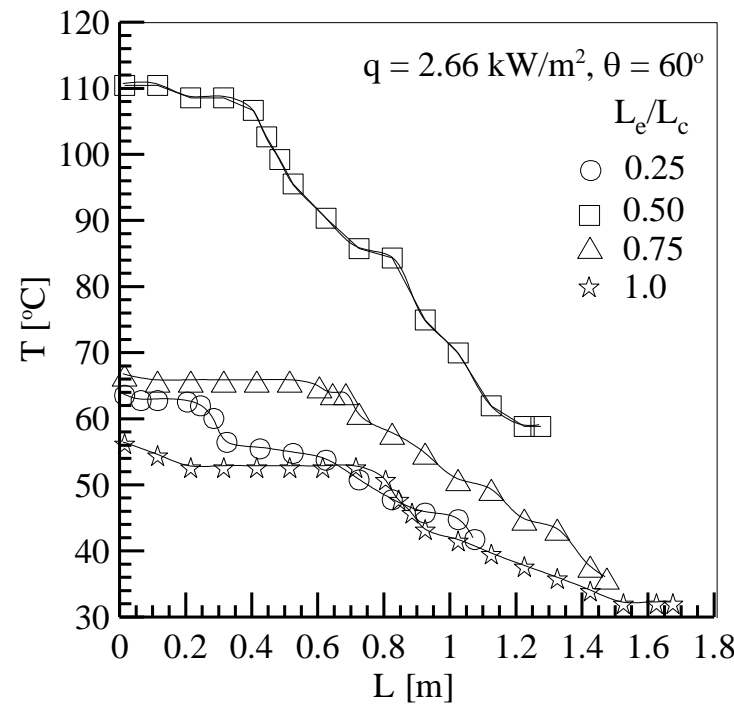

Fig. (5) Wall temperature distribution at different evaporator to condenser length ratio

\section{3-2 Heat Transfer Coefficients:}

The heat transfer mechanism of an inclined two phase closed thermosyphon is an intricate complex consisting of evaporation with or without boiling, steady or unsteady condensation, steady or unsteady condensate rivulet formation and the turbulent dashing motion of liquid. These phenomena depend strongly on the amount of working fluid and the inclination angle. In the present study, the overall heat transfer coefficients in the inclined thermosyphon for practical applications have been obtained. The geometric ratio was chosen to be $\mathrm{L}_{\mathrm{e}} / \mathrm{L}_{\mathrm{c}}$ $=0.25,0.5,0.75$ and 1.0 and inclination angle was $15^{\circ}, 30^{\circ}, 45^{\circ}, 60^{\circ}$ and $90^{\circ}$.

Figures (6 to 13) show the overall heat transfer coefficient $U$ when the inlet cooling water temperature was kept constant at $25{ }^{\circ} \mathrm{C}$. Figures $(6$ and 7) show the dependence of the overall heat transfer coefficient $U$ on the inclination angle and heat flow rate. It is clear that at high heat flux, the overall heat transfer coefficient increases with the increase of inclination angle until it reaches a peak value then it decreases. However, at low heat flux, the heat transfer coefficient is nearly constant. It is noticed that, the optimum inclination angle varies with the operating conditions and thermosyphon geometry. This is because the difference in the potential energy between the condenser and the evaporator is largest and the flying -up distance of the fluid along the tube axis caused by the expansion of the boiling bubbles of the same energy level becomes smaller. Also, in a vertical tube, the film flows downward in axial direction with an approximately constant film thickness around the circumference. 


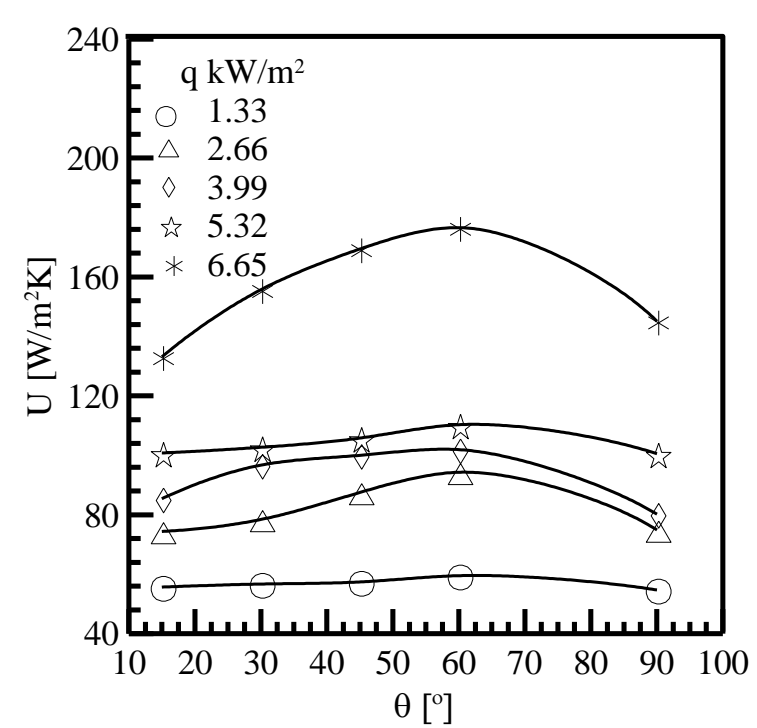

Fig. (6) $U$ - $\theta$ for $L_{e}=L_{c}=0.2 \mathrm{~m}$

On the other hand, in an inclined tube, the condensate flows along a curved path to the lower part of the cross-section where it accumulates and flows back to the evaporator. For small inclination angle, the reduction of axial gravity component is minimum (due to the behavior of the sine function) but the secondary circumferential flow can provide a large relief for the returning liquid film flow. Even when the topside liquid film is retarded, the liquid can still migrate to the underside via the secondary circumferential flow, which makes the underside film thickness (correspondingly the gravitational force) large enough to overcome the shear forces. Also, as the thermosyphon is tilted, the flooding limit at first increased due to the effect of secondary circumferential liquid flow.

For large inclination angle, the reduction of axial gravity component is significant and the flooding limit steeply drops. Also, the overall heat transfer coefficient increases with increasing the heat transfer rate. This is because, with increasing heat flux, more bubbles generate and flying-up to surface where it is converted to vapor. The growth and movement to these bubbles tend to increase the overall heat transfer coefficient.

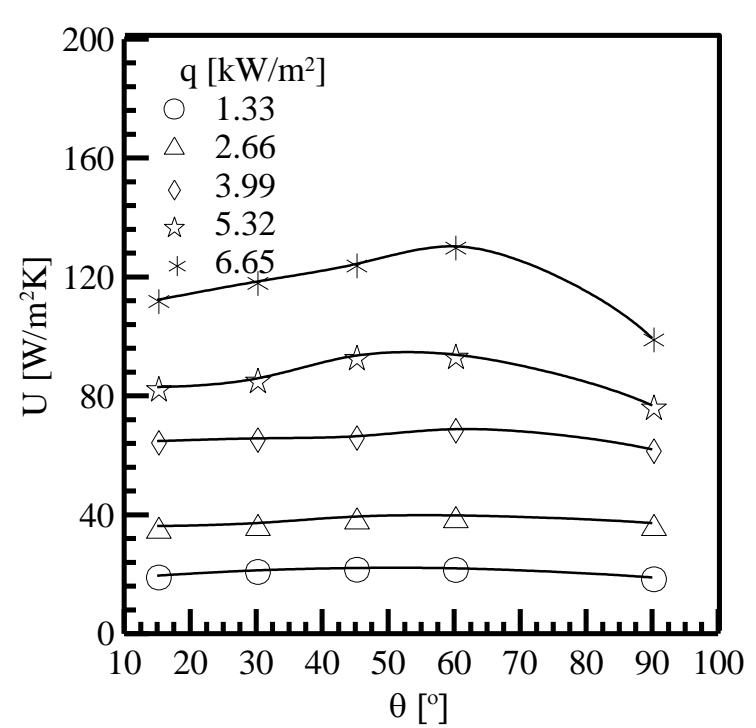

Fig. (7) $U$ - $\theta$ for $L_{e}=L_{c}=0.8 \mathrm{~m}$

Figures ( 8 and 9) show the variation of the overall heat transfer coefficient (U) with the inclination angle at different lengths of both evaporator and condenser and different heat transfer rates. It is obvious that, the overall heat transfer coefficient decreases with increasing the length of both evaporator and condenser.

The behavior of the coefficient (U) in connection with the geometry of both evaporator and condenser can be explored through understanding the flooding phenomenon taking place in the thermosyphon and the gravity force effect at different length of both evaporator and condenser. Besides the difference temperature between the evaporator and condenser affects strongly the overall heat transfer coefficient. With large lengths of both evaporator and condenser, the vapor fraction is decreased, but additional liquid droplets are carried up to the cooled section (condenser). As a result, developed boiling takes place which causes vibration of the thermosyphon, a companied by a deterioration of heat transfer coefficient. 


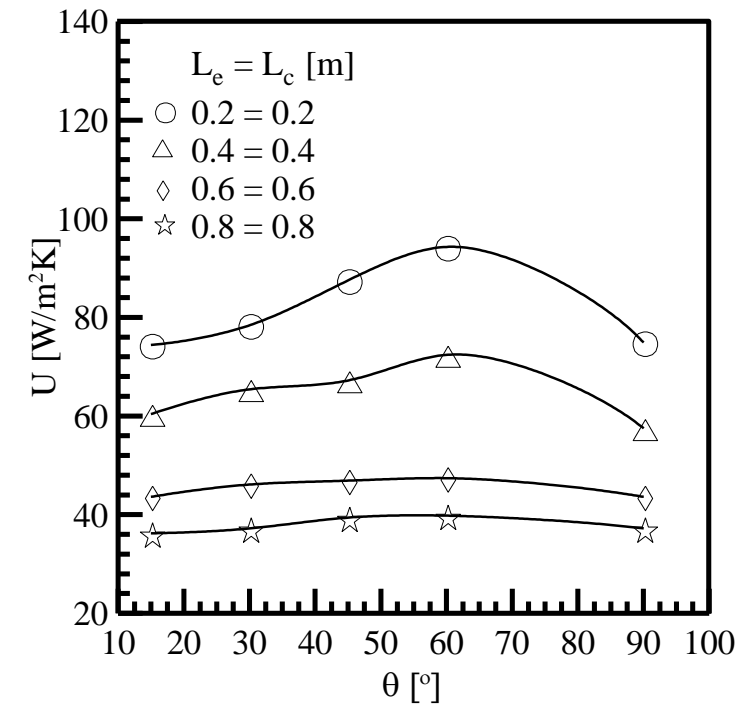

Fig. (8) $U-\theta$ for $q=2.66 \mathrm{kW/m^{2 }}$

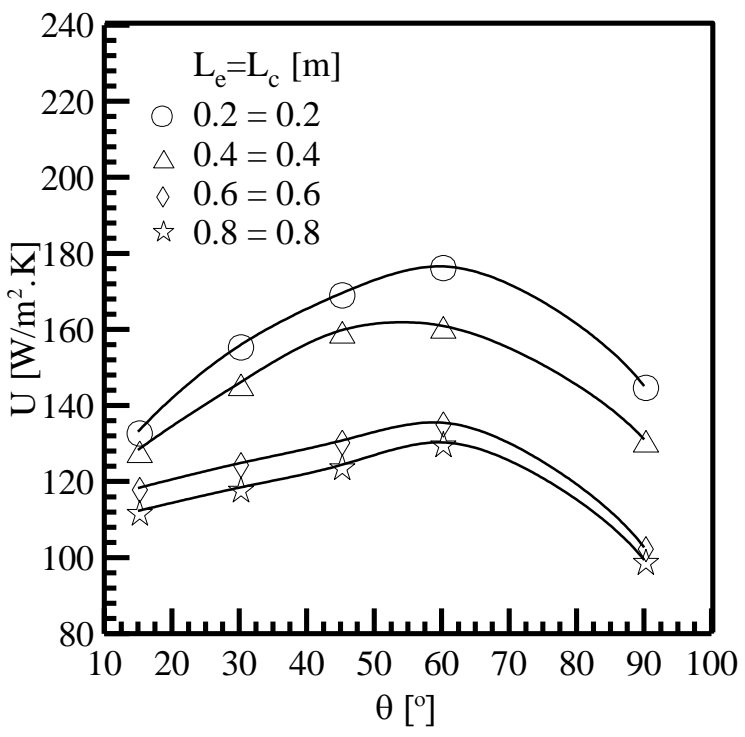

Fig. (9) $U-\theta$ for $q=6.65 \mathrm{~kW} / \mathrm{m}^{2}$

Figures (10 and 11) show the variation of the overall heat transfer coefficient with different geometry ratios $\left(\mathrm{L}_{\mathrm{e}} / \mathrm{L}_{\mathrm{c}}=0.25,0.5,0.75\right.$ and 1.0$)$ at different heat flux. It is noticed that, the values of overall heat transfer coefficient increases with increasing the values $L_{e} / L_{c}$ from 0.25 to 0.5 and then the values of $\mathrm{U}$ decreases with increasing the values of $\mathrm{L}_{\mathrm{e}} / \mathrm{L}_{\mathrm{c}}$ from 0.5 to 1.0 at different heat transfer rates. This means that, the peak values of overall heat transfer coefficient $U$ occurs at $\mathrm{L}_{\mathrm{e}} / \mathrm{L}_{\mathrm{c}}=0.5$. This is referred to the saturated boiling that occupies the long length of the evaporator section resulting in a high vapor fraction. In such case, the convective heat transfer inside the tube becomes so poor. At the same time, due to increased concentration of vapor in the upper condenser section, as well as, the relatively greater saturation.

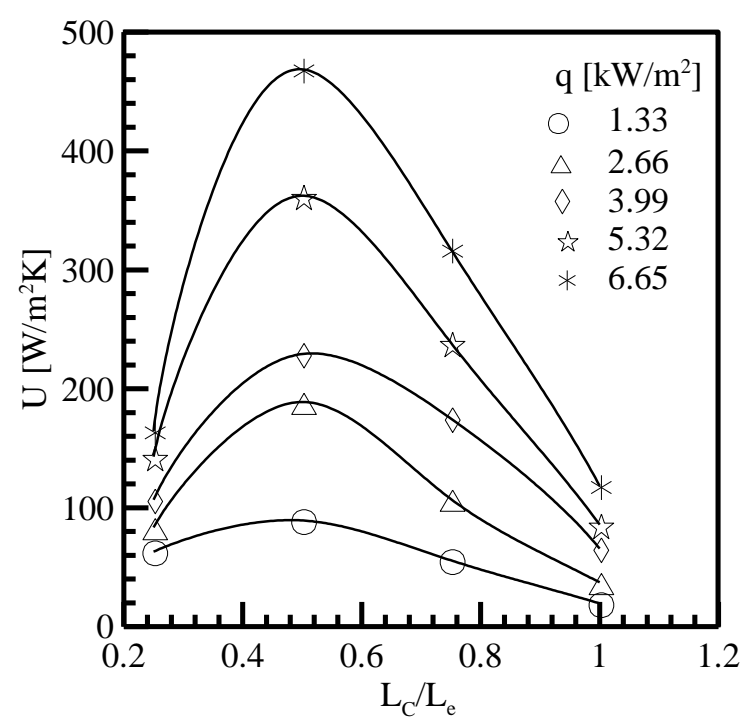

Fig. (10) $U-L_{e} / L_{c}$ for $\theta=30^{\circ}$

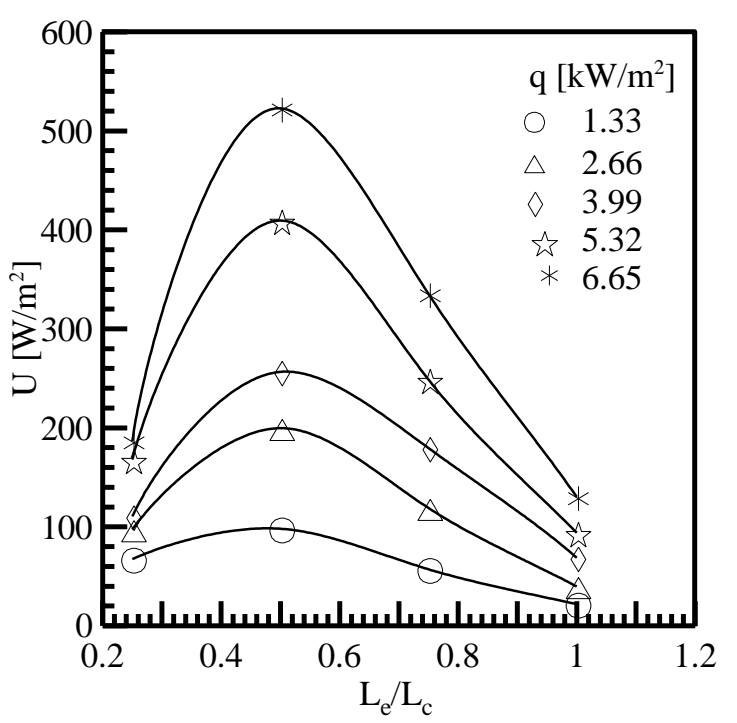

Fig. (11) $U-L_{e} / L_{c}$ for $\theta=60^{\circ}$

At the evaporator section, the generated bubbles coalesce before they are able to separate from the boiling sites and they form a vapor film between the wall and the liquid. Thus, transition from nucleate boiling to film boiling is attained. This results in degradation of the convective boiling heat transfer coefficient, even at rather higher values of heat transfer rate.

The behavior of the overall heat transfer coefficient $\mathrm{U}$ in connection with respect to inclination angle and at different inclination angle is indicated in Figs. (12 and 13). The results in Fig. 12 is taken at heat transfer rate of $2.66 \mathrm{~kW}$ while that in Fig. 13 is taken at heat transfer rate equal to $6.65 \mathrm{~kW}$. It is shown that, the coefficient $U$ is affected with the orientation 
of thermosyphon and its maximum values is attained at $\theta=60^{\circ}$.

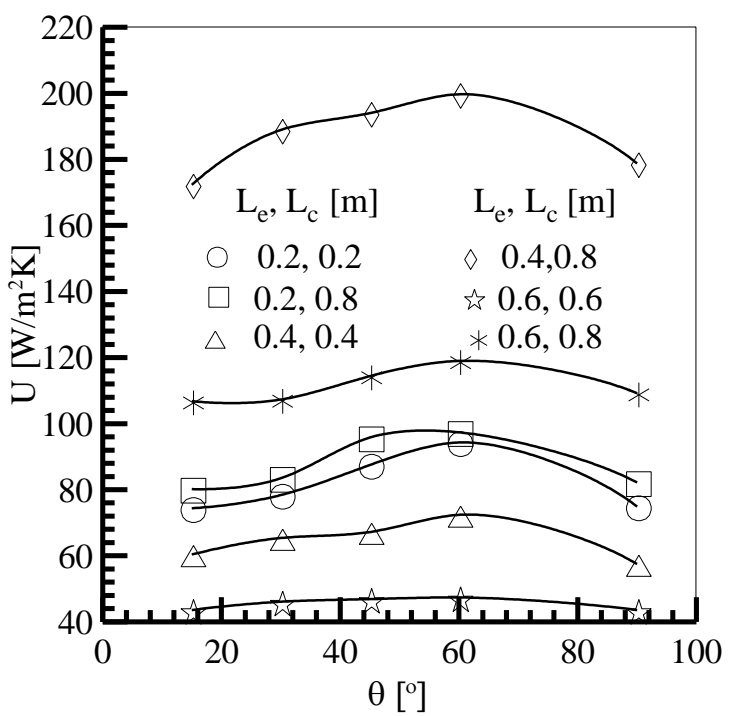

Fig. (12) $U-\theta$ for $q=2.66 \mathrm{~kW} / \mathrm{m}^{2}$

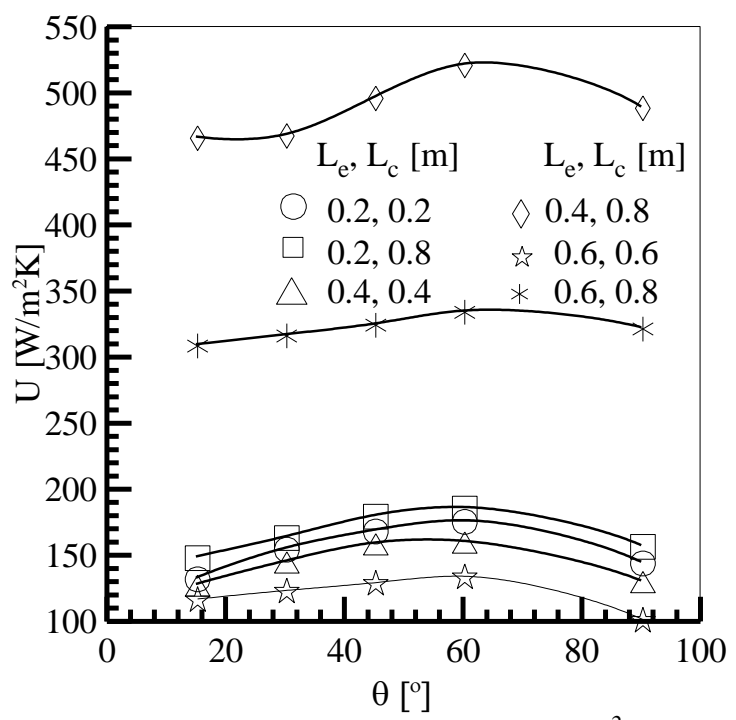

Fig. (13) $U-\theta$ for $q=6.65 \mathrm{~kW} / \mathrm{m}^{2}$

The figures also show the comparison of coefficient $\mathrm{U}$ at different lengths of both evaporator and condenser and the comparison at $\mathrm{L}_{\mathrm{e}} / \mathrm{L}_{\mathrm{c}}=1.0$ at different lengths $\left(\mathrm{L}_{\mathrm{e}}=\mathrm{L}_{\mathrm{c}}=0.2,0.4\right.$ and $\left.0.6 \mathrm{~m}\right)$. It is noticed that, the values of $U$ are maximum at $\mathrm{L}_{\mathrm{e}}=0.4$ $\mathrm{m}$ and $\mathrm{L}_{\mathrm{c}}=0.8 \mathrm{~m}$ while the minimum values of $\mathrm{U}$ is occurred at $\mathrm{L}_{\mathrm{e}}=\mathrm{L}_{\mathrm{c}}=0.6$. This can be attributed to the intensified boiling process at small evaporator area.

\section{Conclusions:}

An experimental work was conducted on the internal heating and cooling offset thermosyphon tube operating at the same heat flux density using water as working fluid. The following are the important conclusions which can be drawn from the reported investigation:

1- The internal cooling -heating offset thermosyphon has higher values of the overall heat transfer coefficient at inclination angle equal to $60^{\circ}$.

2- The optimum value of geometry ratio is at $\mathrm{L}_{\mathrm{e}} / \mathrm{L}_{\mathrm{c}}=$ 0.5 .

3- The maximum values of heat transfer coefficient are at small lengths of both evaporator and condenser.

4- The inclination angle has a substantial influence on the heat transfer coefficient under given temperature conditions and accompanied by a wide range of penalties and benefits.

\section{Nomenclature:}

h convective heat transfer coefficient, $\mathrm{W} / \mathrm{m}^{2} . \mathrm{K}$

$\mathrm{L}$ length, $\mathrm{m}$

$\mathrm{L}^{+}$length ratio $=\mathrm{L}_{\mathrm{c}} / \mathrm{L}_{\mathrm{e}}$

$\mathrm{q}$ heat flux, $\mathrm{W} / \mathrm{m}^{2}$

$\mathrm{T}$ temperature, ${ }^{\circ} \mathrm{C}$

$\mathrm{U}$ overall heat transfer coefficient, $\mathrm{W} / \mathrm{m}^{2} . \mathrm{K}$

\section{Subscripts:}
a adiabatic
c condenser
e evaporator
$\mathrm{m}$ mean

\section{Greek symbols:}

$\theta$ Inclination angle, degree

\section{References:}

[1] Lee, Y. and Mital, U., "A Two phase closed thermosyphon" Int. J. Heat and Mass Transfer, Vol. 15, 1972, pp. 1695-1707.

[2] Bezrodnyy, M. K. and Elekseyenko, D. V. "Boiling heat transfer in closed two phase thermosyphons", Heat transfer- Sov. Res., Vol. 9, 1977, pp. 14-20.

[3] Semana, M. G. and kiseelev, Yu. F., "Heat exchange processes in the heat supply zones of two phase thermosyphons operating on Freon 11, 113, 142 and on water and ethanol" Translated from Inzh-fiz. Zh., Vol. 35, 1978, pp. 211-217.

[4] Andros, F. E. and Florschhueetz, L. W., "The two phase closed thermosyphon: an experimental study with flow visualization in two phase transport and reactor safety" vol. IV, 1976, pp. 111-129.

[5] Rosler, S., Takuma, M., Groll, M. and Maezawa, S., "Heat transfer limitation in a vertical annular closed two phase thermosyphon with small fill rates" Heat 
recovery system CHP, Vol. 7, 1987, pp. 319-327.

1- Shiraishi, M., Kirushi, K. and Yamanishi,T., "Investigation of heat transfer characteristics of a two phase closed thermosyphon", $4^{\text {th }}$ international heat pipe conference, 1982, pp. 95104.

2- Grob, U., "Pool boiling heat transfer inside a two phase thermosyphon-correlation of experimental data." $9^{\text {th }}$ International heat pipe conference, Vol. 2, 1990, pp.57-62.

3- Feldman, K. T. and Srinivassan, S., "Investigation of heat transfer limits in twophase closed thermosyphons" $5^{\text {th }}$ international heat pipe conference, 1984, pp. 30-35.

4- Negishi, K. and Sawada, T., "Heat transfer performance of an inclination two phase closed thermosyphon" Int. J, heat mass transfer, Vol. 26, 1983, pp. 1207-1213.

5- Groll, M., and Spendel, Th., "Thermal behavior of high performance closed two phase thermosyphon", $5^{\text {th }}$ international heat pipe conference, 1984, pp. 1-6.

6- Gross, U. and Hahne, E., "Heat transfer in two phase thermosyphon operating with a fluid in the near critical state", Int. J. Heat mass transfer, Vol. 28, 1985, pp.589-601.

7- Grop U. and Hahne, Th., "Heat transfer in a closed thermosyphon over a wide range of pressures and inclinations" Ger. Chem. Engg. Vol. 9, 1986, pp292-299.

13- A. Nakano, M. Shiraishi, M. Nishio and M. Murakami, "An experimental study of heat transfer characteristics of a two-phase nitrogen thermosyphon over a large dynamic range operation" Cryogenics, Volume 38, Issue 12, December 1998, Pages 1259-1266.

14- Abdel Aziz, M., "Experimental analysis of the optimal performance of closed vertical thermosyphon based on geometry and liquid fill considerations" ICMPE-9, Shebin El-Kom, Egypt, Dec. 21-23, 1996, pp. H4-1-13.

15- Imura, Hideaki; Koito, Yasuhi, Heat Transfer Characteristics in a Two-Phase Crank-Shape Closed Thermosyphon" Transactions of the Japan Society of Refrigerating and Air Conditioning Engineers, Volume 23, Issue 1, pp. 13-23 (2011).

16- M. Kannan and E. Natarajan, "Thermal Performance of a Two-Phase Closed Thermosyphon for Waste Heat Recovery System." Journal of Applied Sciences, 10: 413418, 2010

17- Lock, G. S. H. and Ladoon, D., "The influence of tilt on natural convection in the elbow thermosyphon" Int. J. heat mass transfer, Vol. 36, 1993, pp. 183-188.
18- Lock, G. S. H. and Ladoon, D., "Heat transfer characteristics of the single phase elbow thermosyphon" ASME. J. of heat transfer, Vol. 115, 1993, pp. 173-177.

19- Shung-Wen Kang, Meng-Chang Tsai, ChihSheng Hsieh and Jian-You Chen, "Thermal performance of a loop thermosyphon" Tamkang Journal of Science and Engineering, Vol. 13, 2010, No. 3, pp. 281-288.

20- Lock, G. S. H. and Fu, J., "Natural convection in the inclined cranked thermosyphon" ASME. J. of heat transfer, Vol. 115, Feb. 1993, pp. 166172.

21- Lock, G. S. H. and Ladoon, D., "Natural convection in the cranked thermosyphon" Int. J. heat mass transfer, Vol. 36, 1993, pp. 177-182.

22- Lock, G. S. H. and Fu, J., "Heat transfer characteristics of a cranked evaporative thermosyphon" Int. J. of heat mass transfer, Vol. 36, No. 7, 1993, pp. 1827-1832.

23- Japiksee, D. and Winter, E. R. F., "Single phase transport process in the open thermosyphon" Int. J. heat mass transfer, Vol. 14, 1971, pp. 427441.

24- Lock, G. S. H. and Han, J. C., "Bovyant laminar flow of air in long square section cavity Aligned with ambient temperature gradient" J. of fluid mechanics, Vol. 207, 1989, pp. 489-504.

25- Chi, S. W., "Heat pipes theory and practice" P. 69, McGrow hill, NewYork, 1976. 